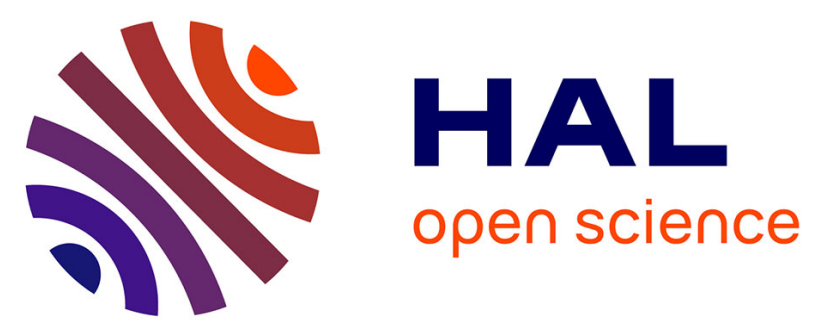

\title{
Structure and resistance to mechanical stress and enzymatic cleaning of Pseudomonas fluorescens biofilms formed in fresh-cut ready to eat washing tanks
}

Charles Cunault, Christine Faille, Almudena Calabozo-Delgado, Thierry Benezech

\section{To cite this version:}

Charles Cunault, Christine Faille, Almudena Calabozo-Delgado, Thierry Benezech. Structure and resistance to mechanical stress and enzymatic cleaning of Pseudomonas fluorescens biofilms formed in fresh-cut ready to eat washing tanks. Journal of Food Engineering, 2019, 262, pp.154-161. 10.1016/j.jfoodeng.2019.06.006 . hal-02617880

\section{HAL Id: hal-02617880 \\ https://hal.inrae.fr/hal-02617880}

Submitted on 25 Oct 2021

HAL is a multi-disciplinary open access archive for the deposit and dissemination of scientific research documents, whether they are published or not. The documents may come from teaching and research institutions in France or abroad, or from public or private research centers.
L'archive ouverte pluridisciplinaire HAL, est destinée au dépôt et à la diffusion de documents scientifiques de niveau recherche, publiés ou non, émanant des établissements d'enseignement et de recherche français ou étrangers, des laboratoires publics ou privés.

\section{(ㄷ)(1) $\$$}

Distributed under a Creative Commons Attribution - NonCommercial| 4.0 International 
1 Structure and resistance to mechanical stress and enzymatic cleaning of Pseudomonas fluorescens

2 biofilms formed in fresh-cut ready to eat washing tanks.

3

$4 \quad$ Author and contact details:

5 Charles Cunault ${ }^{\mathrm{b}}$, Christine Faille ${ }^{\mathrm{a}}$, Calabozo-Delgado Almudena ${ }^{\mathrm{c}}$, Thierry Benezech ${ }^{\mathrm{a}}$

6

7

8

9

aUMR UMET, INRA, CNRS, Univ. Lille, 59650, Villeneuve d'Ascq, France

bUMR1208 IATE, Université de Montpellier, 34095, Montpellier, France

${ }^{\mathrm{c}}$ Realco, 15 Avenue Albert Einstein, 1348 Louvain-la neuve, Belgique

*Corresponding author: Thierry Bénézech

14
Keywords:

Biofilm structure, mechanical detachment, enzymatic cleaning, equipment design, Pseudomonas fluorescens, wetting front

\section{Highlights:}

- Biofilm formation and structure are strongly related to the equipment design

- $\quad$ Resistant biofilms are observed on surfaces at the wetting front

- $\quad$ Biofilms grown under mechanical stress are highly resistant to shear stress

- $\quad$ Biofilms grown on horizontal surfaces are difficult to clean by enzymes 


\section{Introduction}

30

Biofilms are of concern in the food industry, in particular in food processing lines having a negative impact on food quality and food safety and subsequent economic losses (Kusumaningrum et al., 2003). Indeed, much has been written on problems caused by both pathogens and food spoilage bacteria within biofilms (Chmielewski and Frank, 2003). Issues have been reported in various food industries e.g. dairy, poultry, meat fish processing industries (Srey et al., 2013). Among the numerous parameters affecting biofilm formation, the equipment design, including material topography and physico-chemistry would appear to play a major role (Faille et al., 2018). Indeed, biofilms are often found in specific areas including those with surface irregularities (e.g. the rough surface of gaskets or welds or grain boundaries of stainless steel surfaces) and those affecting flow patterns (e.g. dead ends, corners). When biofilms were formed under dynamic conditions, their 3D structures were deeply affected by the flow pattern (Manz et al., 2005; Simões et al., 2006; Stoodley et al., 1999b). More compact and less porous biofilms were observed under turbulent flows than under laminar flow conditions (Stoodley et al., 1999a; Vieira et al., 1993). It has been also stated that biofilm formed under dynamic conditions are healthier and more biologically active than those formed in static conditions (Rochex et al., 2008).

Whatever their formation process once established, biofilms are extremely difficult to control through maintenance procedures, since they are both highly resistant to detachment during cleaning procedures (Bénézech and Faille, 2018; Lemos et al., 2015), as well as being strongly resistant to inactivation during disinfection. In addition, turbulent conditions during biofilm formation would result in biofilms which are more resistant to chemical and mechanical stresses (Chmielewski and Frank, 2003; Lemos et al., 2015; Simões et al., 2006).

For over a decade, the presence of interfaces between substratum, liquid and air has been also suspected of significantly affecting the installation of biofilms. For example, wetting front surfaces would be favourable to bacterial adhesion, as well as to the formation and/or the persistence of biofilms (Giaouris and Nychas, 2006; Wijman et al., 2007; Li et al., 2015). As a consequence, equipment whether partly filled during a process, or where residual liquid has remained after a production cycle, provide ready sites for biofilm formation (Wijman et al., 2007; Cunault et al., 2015) and would therefore contribute to the recurrent contamination of food during further production cycles.

Many efforts have been made to control biofilm development by preventive and curative approaches (Srey et al., 2013). Several strategies have been developed in attempts to prevent biofilm installation, primarily by acting on surface material properties, equipment design, as well as process 
conditions including flow patterns. Removal strategies i.e. the development of efficient cleaning and disinfection procedures have focused mainly on chemical compounds (cleaning and biocide agents) and application means (contact time, temperature).

The aim of this study was to investigate the role of flow patterns and equipment design features, on the biofilm structure after one, two or three days and on their further resistance to chemical vs mechanical actions occurring potentially during cleaning procedures. For this purpose, a series of mock-ups of industrial washing tanks for the fresh-cut food industry (Cunault et al., 2018) was used to study the contamination schemes of Pseudomonas fluorescens biofilms. Resistance to mechanical action was analysed using a flow cell under microscope (Faille et al., 2016) and resistance to cleaning was studied using enzymes in line with industrial foam cleaning practices.

\section{Material and method}

\subsection{Biological material}

P. fluorescens PF1, isolated by ANSES from waste cleaning water, was selected as a model of spoilage bacteria for fresh food industry due to its ability to grow and form biofilms at $10{ }^{\circ} \mathrm{C}$ (Charles Cunault et al., 2015).

\subsection{Pilot rig}

Experiments were performed on a pilot rig (Figure 1) specially designed to mimic the various conditions found in the industrial washing tanks typically employed for fresh cut food products (Cunault et al., 2015). This device is composed of three parts: 1 / the square tube section wherein the flow is unidirectional and turbulent, 2 / the entry vat wherein quasi static conditions are found and 3 / a series of test vats filed by cascade flow providing 3D flow conditions, where fluid is agitated by a Rushton impeller. The device was filled with $73.5 \mathrm{~L}$ of liquid maintained at $10^{\circ} \mathrm{C}$ and was set at a flow

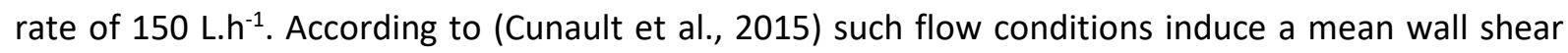
stresses of $0.45 \mathrm{~Pa}$ in the square tubes. In the test vats, the mean wall shear stresses depended on the coupon's location: 0.1 Pa at the corners, between 0.1 and $0.5 \mathrm{~Pa}$ in the folded and welded areas, between 0.25 and $4 \mathrm{~Pa}$ at the horizontal and vertical flat surfaces.

Stainless steel slides of AISI 316 with a 2B finish were placed in the different sections of the rig to follow the formation or detachment of biofilms. Flat slides $\left(1.5 \times 4.5 \mathrm{~mm}^{2}\right)$ were inserted in the square tubes or placed against the inside surfaces of vats. Right-angled coupons, obtained by folding 
or welding, were also placed on the vat surface.

\subsection{Biofilm formation}

Biofilms were grown in the rig at $10^{\circ} \mathrm{C}$ in TSB diluted $1 / 10$ (Tryptone Soy Broth, Biokar, Beauvais, France) inoculated at $10^{6} \mathrm{CFU} \cdot \mathrm{mL}^{-1}$ with an overnight culture of $P$. fluorescens (TSB, $30^{\circ} \mathrm{C}$ ). Biofilms were formed during 24, 48 and $72 \mathrm{~h}$. The surface microbial load, the biofilm structure (SEM observation), and resistance to foam cleaning and mechanical detachment were investigated after 24,48 , and $72 \mathrm{~h}$ after rinsing in reverse osmosed water. Details are given in Table 1.

\subsection{Biofilm analysis}

In order to estimate the amount of biofilms in terms of CFU, biofilms were sampled using cotton swabs (Copan, Brescia, Italy) from the surface of coupons in contact with the suspension. The swabs were previously soaked with peptone water diluted $1 / 10$ with $0.5 \%$ V/V Tween 80 (Sigma-Aldrich, France). Two swabs were used per sample and put into a single container with $10 \mathrm{~mL}$ of the peptoneTween solution. They were subjected to an ultrasonication step ( $2.5 \mathrm{~min}$, Ultrasonic bath, Deltasonic, France) in order to release bacteria from the swab and to homogenize the suspension. The detached bacteria were enumerated on TSA (Tryptone Soy Agar, Biokar, France) after $48 \mathrm{~h}$ at $30^{\circ} \mathrm{C}$.

The biofilm structure was observed by scanning electron microscopy (SEM). As biofilms were easily removed from the surfaces, the contaminated slides were carefully rinsed in osmosed water at a low flow rate for $3 \mathrm{~min}$. The biofilms were then fixed in a 1.25\% glutaraldehyde, $0.1 \mathrm{mM}$ sodium cacodylate $(\mathrm{pH} 7)$ buffer for $48 \mathrm{~h}$, then immersed overnight in a $2 \%$ osmium tetraoxide solution, dehydrated in an ethanol series and lastly subjected to critical point drying. Dehydrated biofilms were then coated with gold-palladium for $1.5 \mathrm{~min}$ and viewed on an S-3000 Hitachi scanning electron microscope operating at $20 \mathrm{kV}$.

\subsection{Biofilm resistance to cleaning}

Biofilm resistance to cleaning was performed using an enzyme foaming agent provided by Realco ${ }^{\circledR}$ (Realco, Louvain-la-Neuve, Belgium). The foam was composed of $0.2 \%$ Biorem 20 (enzymatic mix) and 1\% Enzyfoam (surfactant and enzymes). The enzymatic mix included proteases and polysaccharidases previously shown to efficiently remove biofilms (Lequette et al., 2010). Prior to use, the cleaning solution was placed at $45^{\circ} \mathrm{C}$ for $30 \mathrm{~min}$ to activate the enzymes. The foam was diluted to $5 \%$ in the foam gun and applied twice for 10 min of contact time each. Prior to 
enumeration, surfaces were rinsed twice by streaming of osmosed water and then dried for $30 \mathrm{~min}$ at $30{ }^{\circ} \mathrm{C}$. The number of residual cultivable cells was estimated as described in Section 2.3 , and the biofilm detachment was assessed by comparing the numbers of adherent bacteria before and after cleaning. Any potential effect on the bacteria viability of the chosen enzymatic detergent (mixture of enzymes and surfactant) was checked. Biofilms were therefore covered with the foam for $10 \mathrm{~min}$ and the number of cultivable cells within these treated biofilms was compared to those of untreated biofilms. The variance analysis $(p=0.71)$ indicated that the treatment had no significant effect on the number of cultivable cells (data not shown).

\subsection{Biofilm resistance to mechanical detachment (water flow)}

In order to monitor biofilm resistance to detachment, a parallel-plate flow chamber with a rectangular flow channel (60-mm length by $5-\mathrm{mm}$ width and $0.5-\mathrm{mm}$ height) designed at INRA-PIHM (Faille et al., 2016) was used. For this purpose, contaminated coupons stained with $0.01 \%$ Acridine Orange (Sigma-Aldrich) were put into the flow chamber and subjected to 30-second steps of increasing flow rates of deionised water at room temperature (wall shear stresses of 17, 33, 93, 167, 241, and $310 \mathrm{~Pa})$.

The bacterial detachment over time was monitored under microscope (Axioskop 2 plus, Zeiss) by epifluorescence on an area of about $130 \times 100 \mu \mathrm{m}^{2}$, which is considered to be representative of the whole surface contamination. Images at TO and at the end of each detachment step were recorded by camera (Olympus DP21, France) at a magnification of $\times 400$. The number of adherent cells or, when the coverage was too high for cell enumeration, the percentage of surface covered with biofilms were quantified using image analysis (ImageJ software). Biofilm detachment was assessed by the ratio of the number of cells remaining after each flow rate step to the number of cells at TO.

\subsection{Statistical analyses}

Two sets of experiments were conducted. For each set of experiments, trials were carried out at least in triplicate, with at least two coupons for each trial.

Data were analysed by general linear model procedures using SAS V9.4 software (SAS Institute, Gary, NC, USA). Variance analyses were performed to determine the impact of coupon location, age of biofilm and trial, on the amount of biofilm in terms of CFU. These were followed by multiple comparison procedures using Tukey's grouping (Alpha level $=0.05$ ). Other sets of variance analyses and Tukey's grouping were performed to determine: the role of coupon location, the age of the biofilm, the trial, the wall shear stress or enzyme action on the biofilm detachment. 


\section{Results}

170

171

172

173

174

175

176

177

178

179

180

181

182

183

184

185

186

187

188

189

190

191

192

193

194

195

196

197

198

199

200

201

202

\subsection{Biofilm formation}

The average numbers of cultivable cells on each area (square tubes, entry vat ( $\mathrm{H}$-static and Vstatic) and reference vats (other areas) are given in Table 2 . After $24 \mathrm{~h}$ growth, clear differences were observed in the numbers of cultivable cells (between 7.8 and $1.310^{6}$ CFU.cm ${ }^{-2}$ ). The vertical (V-VAT) flat surface of the test vats was the least contaminated. Four other areas were poorly contaminated with between $1.210^{3}$ and $7.410^{3} \mathrm{CFU} . \mathrm{cm}^{-2}$, namely the other two flat surfaces, horizontal (H-VAT) and partially immersed surfaces corresponding to a wetting front (Interface), but also the vertical weld (V-WELD) and horizontal fold (H-FOLD). Lastly, the greatest amounts of biofilm were observed on both horizontal (H-STAT) and vertical (V-STAT) surfaces in the entry vat (quasi-static conditions). Whatever the area, the surface contamination further increased with time to reach values ranging from $3.110^{5}$ to $1.910^{8} \mathrm{CFU} . \mathrm{cm}^{-2}$ after $72 \mathrm{~h}$. The V-VAT were still poorly contaminated, followed by the H-FOLD, but the observed differences were less pronounced than after $24 \mathrm{~h}$. It is noteworthy that both surfaces of the entry vat ( $\mathrm{H}$ - and V-STA), in quasi-static conditions, were still among the three most contaminated surfaces, whatever the duration of biofilm formation. The newly highly contaminated coupons were those inserted into the tubes.

Statistical analysis confirmed these observations. The variance analysis, which took into account the biofilm location, trial and duration of biofilm formation (Table 3), showed that the three parameters accounted for $76 \%$ of the variability and that each played a significant role $(p<0.0001)$. Further variance analyses were performed for each duration of biofilm formation. The differences observed in the number of CFU on the different areas were still largely attributed to the two remaining parameters (location and trial type), at least at $24 \mathrm{~h}$ ( $83 \%$ of the variability) and at $48 \mathrm{~h}$ (74\%). Results also clearly indicated that the amount of CFU was affected by the biofilm location ( $p<$ 0.0001). The influence of the trial increased with the age of the biofilm, to become significant after $72 \mathrm{~h}$.

According to the Tukey's groupings performed for each duration of biofilm formation (Table 2), significant differences were observed between some locations. For example, the $\mathrm{H}$ - and V-STATIC locations (quasi-static conditions) were significantly more contaminated than the surfaces of the test Vats, except the corners (at 24, 48 and $72 \mathrm{~h}$ ) and the H-WELD (at $24 \mathrm{~h}$ ). On the other hand, the vertical surfaces of the vats (V-VAT) were significantly the least contaminated whatever the biofilm age. However, biofilms grown at the interface being also on a vertical wall appeared to be at an intermediate level. On the other hand, the vertical surfaces of the vats (V-VAT) were significantly the 
least contaminated surface, whatever the of biofilm age. However, biofilms grown at the interface being also on a vertical wall were at an intermediate contamination level.

\subsection{The SEM observations}

SEM observations were performed on $72 \mathrm{~h}$-biofilms produced on coupons inserted into square tubes or placed against the surfaces of the entry and test vats. Due to difficulties encountered in maintaining coupons in position in the H-VAT and V-VAT, the observation of vertical and horizontal surfaces of the test-vats was performed on the horizontal and vertical sides of the H-WELD and HFOLD coupons.

The amount and distribution of biofilms over the tested surfaces are shown in Figures 2 and supplementary data 1 . The distribution largely depended on the sampling zone. For example, the highest bacterial density was observed at the interface zone (Figure 2, left part), while surfaces located at the welds or the folds (Supplementary File 1 ) were only slightly contaminated with the presence of few clusters (mainly located in the surface defects) separated by wide zones with single cells or devoid of any contamination. These results are broadly consistent with the enumeration data. Concerning the biofilm structures (Figures 2 and 3), cell clusters or even 3-D structures were clearly observed on most surfaces, suggesting the presence of complex biofilms along with single cells or small cell clusters. As visible on the surface of the square tube, cell clusters were sometimes long and narrow, forming ripple-like structures mainly parallel to the flow direction (white arrow). Small ridge-like structures were also seen on the H-WELD and H-FOLD surfaces, but their orientation was strongly affected by their location (vertical side, horizontal side, bending/welding areas) probably as the result of flow organisation. Conversely, those clusters formed in static conditions were rounded (V-and H-STAT) or slightly elongated in all directions (H-STAT). Lastly at the interface (Figure 3), the dense cell clusters were flat and interspersed with poorly contaminated areas in the fully immersed zone, seeming to coalesce to form large and flat aggregates in the intermittently immersed interface zone.

In order to observe the biofilm structures in detail, further observations were performed at stronger magnification (Figures $3-A,-B$ and $-C$ and Supplementary data 1). Extracellular material was clearly observed when biofilms were produced in tubes (Supplementary data 1-A, white arrow), while at best, only small quantities of exopolymers were produced in the other areas (Supplementary data $1-B,-D$ and $-H$ ). Anecdotally, it can also be noted that many bacteria were located in the depth of grain boundaries on the upper part of the interface zone (Figure 3-A) and that these surface irregularities would probably provide protection against shear stresses during process and during hygiene procedures. 
Five areas (flat surfaces) were kept for further experiments on bacterial detachment in the flow cell under microscope. Detachment experiments were performed at increasing wall shear stresses $(17,60,130,190,275$, and $360 \mathrm{~Pa})$ using deionised water at room temperature. As shown in Figure 4, great differences in the resistance to detachment were obtained regardless of the age of the biofilms (Figures 4-A, -B and -C): biofilms grown on V-VAT and at interface were systematically the most resistant to detachment. Elsewhere, most biofilms became more resistant to detachment with time, such as biofilms at interfaces, whose percentage of residual biofilm increased from $74 \%$ after $24 \mathrm{~h}$ to $90 \%$ after $48 \mathrm{~h}$ of biofilm growth. The contrary was observed when biofilms were grown in V-VAT conditions with average values of 87,83 and $72 \%$ residual biofilm after 24 h, 48 h, and 72 h, respectively. Concerning the influence of shear stress, little $(<20 \%)$ or no detachment was observed at $17 \mathrm{~Pa}$. Conversely when biofilms were subjected to higher shear stresses, great differences were observed between areas in the ease of biofilm detachment, with percentages of residual biofilm ranging from less than 10\% (24 h-biofilms in V-STAT, H-STAT and pipes) to around over $75 \%$ (48 hand $72 \mathrm{~h}$-biofilms at the interface).

Taking into account the whole set of data (Table 4), the variance analysis indicated that all the three parameters: wall shear stress (WSS), location, and trial type significantly affected the resistance of biofilms to detachment ( $p$-values $<0.0001,<0.0001,=0.0005$, respectively), while the age of biofilms did not $(p=0.1162)$. Further variance analyses were performed for each wall shear stress. As shown in Table 4, the ease of removal of biofilms was significantly affected by the biofilm location, whatever the shear stress $(p<0.0001)$, yet not at all or only to a very limited extent by the age of biofilms. Tukey's grouping showed that, regardless of the wall shear stress, the amount of residual biofilm was one of the highest when biofilm growth occurred at the interface and one of the lowest when biofilm growth occurred in H-STAT conditions.

\subsection{Resistance to enzymatic cleaning}

Data are presented in Figure 5. Great differences among zones were observed in the residual ratio of biofilms after cleaning varying from 1 (no removal) down to 0.01 (99\% removal). The most difficult to clean areas to clean were the three horizontal surfaces and the corner. A wide distribution of the data could be observed in these areas. Conversely, vertical areas and coupons located in tubes were more cleanable with a lower range of data distribution. Interface area data differed from the other cases by a wide variability comparable to those areas difficult to clean and by a low median value 
comparable to easy-to-clean areas. SEM observations of H-FOLD and H-WELD in Supplementary File 2 confirmed the low cleanability of both locations with a significant remaining amount of bacteria, but without any visible clusters. Conversely, SEM observations showed that a significant residual contamination was also present on the surfaces located at the interface, with the presence of cell clusters.

The analysis of variance (Table 4) indicated that the location and trial type significantly affected the resistance of biofilms to detachment ( $p$-values $<0.0001,=0.0122$ respectively), while the age of biofilms did not $(p=0.91)$. Tukey's grouping (Table 5.2) confirmed that biofilms grown on horizontal surfaces comprising design defaults (welds, folds and corners (group A)) were more difficult to clean than vertical surfaces and tubes (group C). Lastly, the interface residual ratio was at an intermediate level (group $A B C$ ), due to the wide variation between trials.

\section{Discussion}

Experiments were carried out with mock-ups of vats designed to be close to those encountered in the fresh-cut food industry including pipes commonly present in processing lines. The vat design was chosen to reproduce some specific features to evidence their criticality in terms of hygiene while circulating water contaminated with a Pseudomonas strain. A strong influence of the design on biofilm development and shape and their further resistance to shear stress and enzymatic cleaning was clearly observed. Available literature reports numerous studies on how the flow conditions affect biofilm formation and properties. Some authors (Chmielewski and Frank, 2003; Dunsmore et al., 2002; Purevdorj et al., 2002; Stoodley et al., 1999b) and more recently (Brugnoni et al., 2011, 2012); Hödl et al., 2014) have shown that unidirectional flow reduces the degrees of freedom of migrating cells and cluster coalescence to spread spatially, thereby inducing elongated shape biofilm structures. This phenomenon induces the cluster anisotropy clearly observed in this study for biofilms grown in pipes. However, such elongated shape clusters were also observed for biofilms formed in vats in every area largely affected by the flow recirculation induced by the impeller, either on bend zones (with welds or not), or simply on vertical and horizontal surfaces. Such a pattern is different from the ripple-shaped pattern (perpendicular to the flow) described by (Cogan et al., 2018), taking into account the oscillatory phenomenon induced by the flow. In addition to the morphology, hydrodynamics affects cell density and biofilm matrix composition. The fluid velocity field in contact with the attached microbial layer is widely considered as one of the most important factors affecting biofilm structure and activity (Araújo et al., 2016; Liu and Tay, 2002; Pereira et al., 2002) greatly exceeding the influence of factors such as biofilm age, suspended cell concentration, $\mathrm{pH}$, surface roughness of the substratum (Chen et al., 2005). Indeed, biofilm volumetric density and EPS volume increase with the shear stress, resulting in an increased biofilm cohesion (Garny et al., 
2008; Simões et al., 2010). Such statements were confirmed here with a stronger resistance to shear of observed for biofilms grown under dynamic conditions on the vat walls directly affected by the flow movements induced by the impeller. Hence, such biofilms were the ones presenting the most remarkable increased between $24 \mathrm{~h}$ and $72 \mathrm{~h}$ with almost 5 Log. Santos et al. (1991) reported much thicker biofilms of $P$. fluorescens at $2.5 \mathrm{~m} \mathrm{~s}^{-1}$ than at $0.5 \mathrm{~m} \mathrm{~s}^{-1}$ leading to a more stable biofilm. In addition, V-Vat biofilms presented oriented clusters due probably to the flow arrangement at the wall surface as previously observed (Brugnoni et al., 2012). Cells in contact with flowing become oriented so that each cell offers the least resistance to flow possibly corresponding to the natural elimination of cells susceptible to shear forces when the biofilm grow due to their position in relation to the flow. It should be mentioned that very high shear stresses (over $300 \mathrm{~Pa}$ ) were used here, while those encountered in food processing lines barely exceed $100 \mathrm{~Pa}$. Such a high resistance to the shear stress was also observed for biofilm grown at the interface. This resistance could be the result of the conditions encountered during biofilm formation at the wetting front along with the periodic wetting induced by the impeller rotation. Even if it is not at the same scale wetting front detrimental effects are known in other environment as marine environment but not in terms of biofouling but in terms of active corrosion. All splash areas were found to deeply limit the lifespan of reinforced concrete marine structures and considered as accelerated high water corrosion zone compared to low water corrosion zones that pass from air, i.e. above high tide level into sea water to below low tide level (Mackie, 2008). However, it is largely admitted that thick biofilms often preferentially develop at the interface, rather than in wholly submerged areas. Biofilms at the interface has been reported in the literature, but only in laboratory conditions. Some authors including (Wijman et al., 2007) have suggested that such biofilms may develop particularly in partly-filled devices such as industrial storage and piping systems during process or after the cleaning procedure in areas with residual liquid. All these surfaces should be recognized as actual critical points in terms of surface hygiene in the food processing lines or environments.

A recent review (Nahar et al., 2018) described the advances in biofilm impairment strategies in the food industry. Among these strategies, enzymes were put forward as an alternative to chemical agents as previously demonstrated (Lequette et al., 2010). Commercial enzyme formulations contain mixtures of enzymes with different substrate spectra. Enzymatic processes have the advantage of disaggregating biofilm clumps rather than just removing them from the surface, as is the case with mechanical action (Bridier et al., 2011). According to a recent work performed in our laboratory on Cleaning-In-Place kinetics of surfaces contaminated by Pseudomonas fluorescens biofilms (Bénézech and Faille, 2018), the $\mathrm{NaOH}$ chemical action acted mainly on the biofilm matrix, inducing a disruption of the clusters at the early phase of the kinetics, while the mechanical action also acted on the cells directly in contact with the surface. When using an enzymatic cocktail, the ease of cleaning was 
enhanced for vertical surfaces compared to horizontal ones, interface biofilms being at an

344 intermediate level. Biofilms in tubes also appeared to be less resistant to enzymes. Conversely, the 345 dynamic vs static conditions during biofilm growth did not affect the cleaning efficiency. (Lemos et 346 al., 2015) working on Bacillus biofilms, did not find any influence on the cleaning efficiency of the growth conditions, turbulent or laminar either. In this work, despite their specific surface features, welds surprisingly were cleanable when vertical but not when horizontal. This is in line with previous papers stating no relationship between welding zones and bacterial adhesion (Casarin et al., 2014) or bacterial colonization (Tide et al., 1999). Nevertheless, the resistance to cleaning seems to be related to the design features in accordance to EHEDG principles (Hofmann et al., 2018), which states that horizontal surfaces and corners should be avoided. Lastly the interface zone which can be considered to be hygienic according to EHEDG (vertical wall) appeared here to be poorly hygienic. Any surface regularly splashed without regular cleaning and prone to drying, may therefore represent hygienic issues, which are likely to result in a resident contamination in the factory site. Design requirements stated in the sole European standard concerning the basic concepts on hygiene requirements of food processing machineries (EN 1672-2:2006+A1:2009 Food processing machinery - Basic concepts - Part 2: Hygiene requirements) differentiates the presence or not of food (food and non-food areas) and the splash area. Splash areas shall be designed and constructed following the same principles for the food areas. The concept of 'no return to the food area' is imperative and lead to less stringent design criteria: in the washing tanks splashed areas are part of the food area as the splashed washing water may contain food (piece of fresh-cut vegetables) being able to go back to the tank to be eventually packed and ready for delivery to the consumer.

\section{Conclusion}

It was demonstrated in conditions close to those encountered in vegetable processing industry, that some specific areas within industrial washing tanks are prone to allowing a strong bacterial contamination and generating a further high resistance to rinsing/cleaning processes. In addition to those areas already identified as poorly hygienic (welds, corners, horizontal surfaces), the interface zones corresponding to the wetting front should also be considered as a place conducive to the installation of resistant bacterial contamination. Importance of the design appeared here not only in terms of ease of cleaning but in terms of surface contamination. In actual washing tanks in use in the

374 fresh-cut industry, design principals encountered are those of this study washing tanks. Thus, any 375 modifications such as open angles, no horizontal surfaces, no right corners would thus significantly 376 change the contamination scheme and minimise further resistance to cleaning and make the 377 conclusions of this study directly applicable. It should be kept in mind that interface zones should be 
378 considered to improve the hygienic level of the whole equipment and lines. This would allow 379 industrialists to envisage the use of more environmentally-friendly cleaning procedures complying 380 with new environmental constraints.

381

382

\section{Acknowledgments}

383 This work was undertaken under the European Research Project SUSCLEAN (contract number FP7-

384 KBBE-2011-5, project number: 28514). We are grateful to Jean-François Migdal, Jacky Six and Laurent 385 Wauquier for their involvement in this work. We also thank the trainees Olivier Behague, Jonathan 386 Braquis and Mickaël Pollet for their valuable contribution.

387

388

389 
Araújo, P.A., Malheiro, J., Machado, I., Mergulhão, F., Melo, L., Simões, M. (2016). Influence of Flow Velocity on the Characteristics of Pseudomonas fluorescens Biofilms. Journal of Environmental Engineering 142, 04016031.

Bénézech, T., Faille, C. (2018). Two-phase kinetics of biofilm removal during CIP. Respective roles of mechanical and chemical effects on the detachment of single cells vs cell clusters from a Pseudomonas fluorescens biofilm. Journal of Food Engineering 219, 121-128.

Bridier, A., Briandet, R., Thomas, V., Dubois-Brissonnet, F. (2011). Resistance of bacterial biofilms to disinfectants: A review. Biofouling 27, 1017-1032.

Brugnoni, L.I., Cubitto, M.A., Lozano, J.E. (2011). Role of shear stress on biofilm formation of Candida krusei in a rotating disk system. Journal of Food Engineering 102, 266-271.

Brugnoni, L.I., Cubitto, M.A., Lozano, J.E. (2012). Candida krusei development on turbulent flow regimes: Biofilm formation and efficiency of cleaning and disinfection program. Journal of Food Engineering 111, 546-552.

Casarin, L.S., Brandelli, A., de Oliveira Casarin, F., Soave, P.A., Wanke, C.H., Tondo, E.C. (2014). Adhesion of Salmonella enteritidis and Listeria monocytogenes on stainless steel welds. International Journal of Food Microbiology 191, 103-108.

Chen, M.J., Zhang, Z., Bott, T.R. (2005). Effects of operating conditions on the adhesive strength of Pseudomonas fluorescens biofilms in tubes. Colloids and Surfaces B: Biointerfaces 43(2),6171

Chmielewski, R.A.N., Frank, J.F. (2003). Biofilm formation and control in food processing facilities. Comprehensive Reviews in Food Science and Food Safety 2, 22-32.

Cogan, N.G., Li, J., Fabbri, S., Stoodley, P. (2018). Computational Investigation of Ripple Dynamics in Biofilms in Flowing Systems. Biophysical Journal 115, 1393-1400.

Cunault, Charles, Faille, C., Bouvier, L., Föste, H., Augustin, W., Scholl, S., Debreyne, P., Benezech, T. (2015). A novel set-up and a CFD approach to study the biofilm dynamics as a function of local flow conditions encountered in fresh-cut food processing equipment. Food and Bioproducts Processing 93, 217-223.

Cunault, C., Faille, C., Briandet, R., Postollec, F., Desriac, N., Benezech, T. (2018). Pseudomonas sp. biofilm development on fresh-cut food equipment surfaces - a growth curve - fitting approach to building a comprehensive tool for studying surface contamination dynamics. Food and Bioproducts Processing 107.

Dunsmore, B.C., Jacobsen, A., Hall-Stoodley, L., Bass, C.J., Lappin-Scott, H.M., Stoodley, P. (2002). The influence of fluid shear on the structure and material properties of sulphate-reducing bacterial biofilms. Journal of Industrial Microbiology and Biotechnology 29, 347-353.

Faille, C., Bihi, I., Ronse, A., Ronse, G., Baudoin, M., Zoueshtiagh, F. (2016). Increased resistance to detachment of adherent microspheres and Bacillus spores subjected to a drying step. Colloids and Surfaces B: Biointerfaces 143, 293-300.

Faille, C., Cunault, C., Dubois, T., Bénézech, T. (2018). Hygienic design of food processing lines to mitigate the risk of bacterial food contamination with respect to environmental concerns. Innovative Food Science and Emerging Technologies 46, 65-73.

Garny, K., Horn, H., Neu, T.R. (2008). Interaction between biofilm development, structure and detachment in rotating annular reactors. Bioprocess and Biosystems Engineering 31, 619629.

Giaouris, E.D., Nychas, G.J.E. (2006). The adherence of Salmonella enteritidis PT4 to stainless steel: The importance of the air-liquid interface and nutrient availability. Food Microbiology 8, 747752.

Hödl, I., Mari, L., Bertuzzo, E., Suweis, S., Besemer, K., Rinaldo, A., Battin, T.J. (2014). Biophysical controls on cluster dynamics and architectural differentiation of microbial biofilms in contrasting flow environments. Environmental Microbiology 16(3), 802-812 
Hofmann, D.J., Åkesson, S., Curiel, G., Woulters, D.P., Timperley, A. (2018). Hygienic Design Principles. European Hygienic Engineering \& Design Group Guidelines 8.

Kusumaningrum, H.D., Riboldi, G., Hazeleger, W.C., Beumer, R.R. (2003). Survival of foodborne pathogens on stainless steel surfaces and cross-contamination to foods. International Journal of Food Microbiology 85, 227 - 236.

Lemos, M., Mergulhão, F., Melo, L., Simões, M. (2015). The effect of shear stress on the formation and removal of Bacillus cereus biofilms. Food and Bioproducts Processing 93, 242-248.

Lequette, Y., Boels, G., Clarisse, M., Faille, C. (2010). Using enzymes to remove biofilms of bacterial isolates sampled in the food-industry. Biofouling 26, 421-431.

Li, B., Liu, X.-C., Li, L., Xu, Z.-B. (2015). Molecular identification of the genotype of Staphylococcus aureus biofilm. Modern Food Science and Technology 31(7), 74-79.

Liu, Y., Tay, J.H. (2002). The essential role of hydrodynamic shear force in the formation of biofilm and granular sludge. Water Research 36(7),1653-1665.

Mackie, K.P. (2008) Accelerated high water corrosion. in Alexander, M., Beushausen, H.-D., Dehn, F., Moyo, P. (Eds.) (2008). Concrete Repair, Rehabilitation and Retrofitting II: 2nd International Conference on Concrete Repair, Rehabilitation and Retrofitting, ICCRRR-2, 24-26 November 2008, Cape Town, South Africa. CRC Press.

Manz, B., Volke, F., Goll, D., Horn, H. (2005). Investigation of biofilm structure, flow patterns and detachment with magnetic resonance imaging. Water Science and Technology 52, 1-6.

Nahar, S., Mizan, M.F.R., Ha, A.J. won, Ha, S. Do (2018). Advances and Future Prospects of EnzymeBased Biofilm Prevention Approaches in the Food Industry. Comprehensive Reviews in Food Science and Food Safety 17, 1484-1502.

Pereira, M.O., Kuehn, M., Wuertz, S., Neu, T., Melo, L.F. (2002). Effect of flow regime on the architecture of a Pseudomonas fluorescens biofilm. Biotechnology and Bioengineering 78, 164-171.

Purevdorj, B., Costerton, J.W., Stoodley, P. (2002). Influence of hydrodynamics and cell signaling on the structure and behavior of Pseudomonas aeruginosa biofilms. Applied and Environmental Microbiology 68(9), 4457-4464.

Rochex, A., Godon, J.J., Bernet, N., Escudié, R. (2008). Role of shear stress on composition, diversity and dynamics of biofilm bacterial communities. Water Research 42(20), 4915-22.

Santos, R., Callow, M.E. and Bott, T.R. (1991) The structure of Pseudomonas fluorescens biofilms in contact with flowing systems. Biofouling 4, 319-336.

Simões, M., Simões, L.C., Machado, I., Pereira, M.O., Vieira, M.J. (2006). Control of Flow-Generated Biofilms with Surfactants. Food and Bioproducts Processing 84, 338-345.

Simões, M., Simões, L.C., Vieira, M.J. (2010). A review of current and emergent biofilm control strategies. LWT - Food Science and Technology 43, 573-583.

Srey, S., Jahid, I.K., Ha, S.D. (2013). Biofilm formation in food industries: A food safety concern. Food Control 31, 572-585.

Stoodley, P., Dodds, I., Boyle, J.D., Lappin-Scott, H.M., (1999a). Influence of hydrodynamics and nutrients on biofilm structure. J. Appl. Microbiol. Symposium Supplement 85, 19S-28S.

Stoodley, P., Lewandowski, Z., Boyle, J.D., Lappin-Scott, H.M., (1999b). The formation of migratory ripples in a mixed species bacterial biofilm growing in turbulent flow. Environmental Microbiology 1, 447-455.

Tide, C., Harkin, S.R., Geesey, G.G., Bremer, P.J., Scholz, W. (1999). Influence of welding procedures on bacterial colonization of stainless steel weldments. Journal of Food Engineering 42, 85-96.

Vieira, M.J., Melo, L.F., Pinheiro, M.M. (1993). Biofilm formation: hydrodynamic effects on internal diffusion and structure. Biofouling 7, 67-80.

Wijman, J.G.E., De Leeuw, P.P.L.A., Moezelaar, R., Zwietering, M.H., Abee, T. (2007). Air-liquid interface biofilms of Bacillus cereus: Formation, sporulation, and dispersion. Applied and Environmental Microbiology 73(5), 1481-1488. 


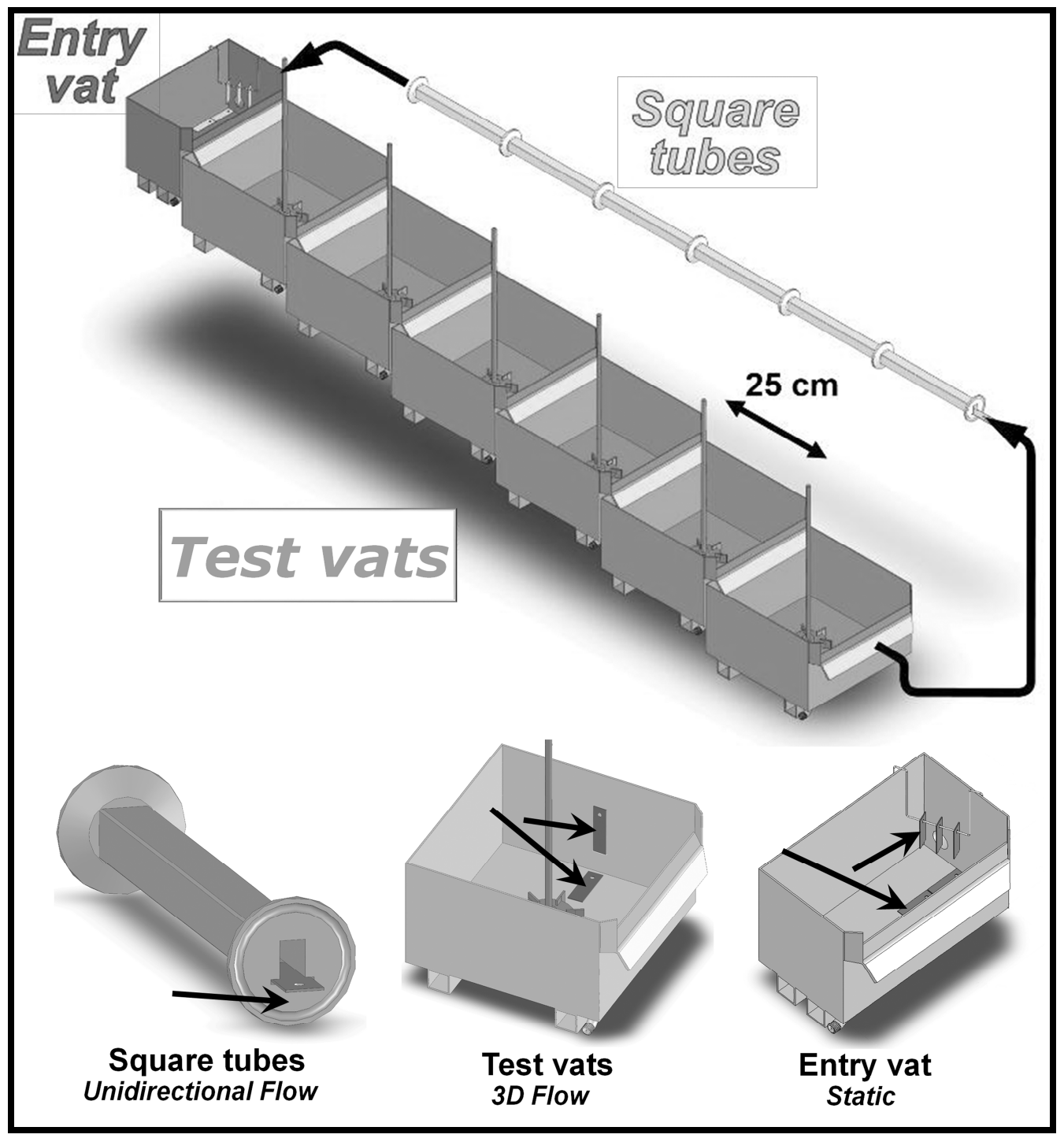

Figure 1: Schematic representation of the pilot rig. The black arrows indicate the location of the coupons. 


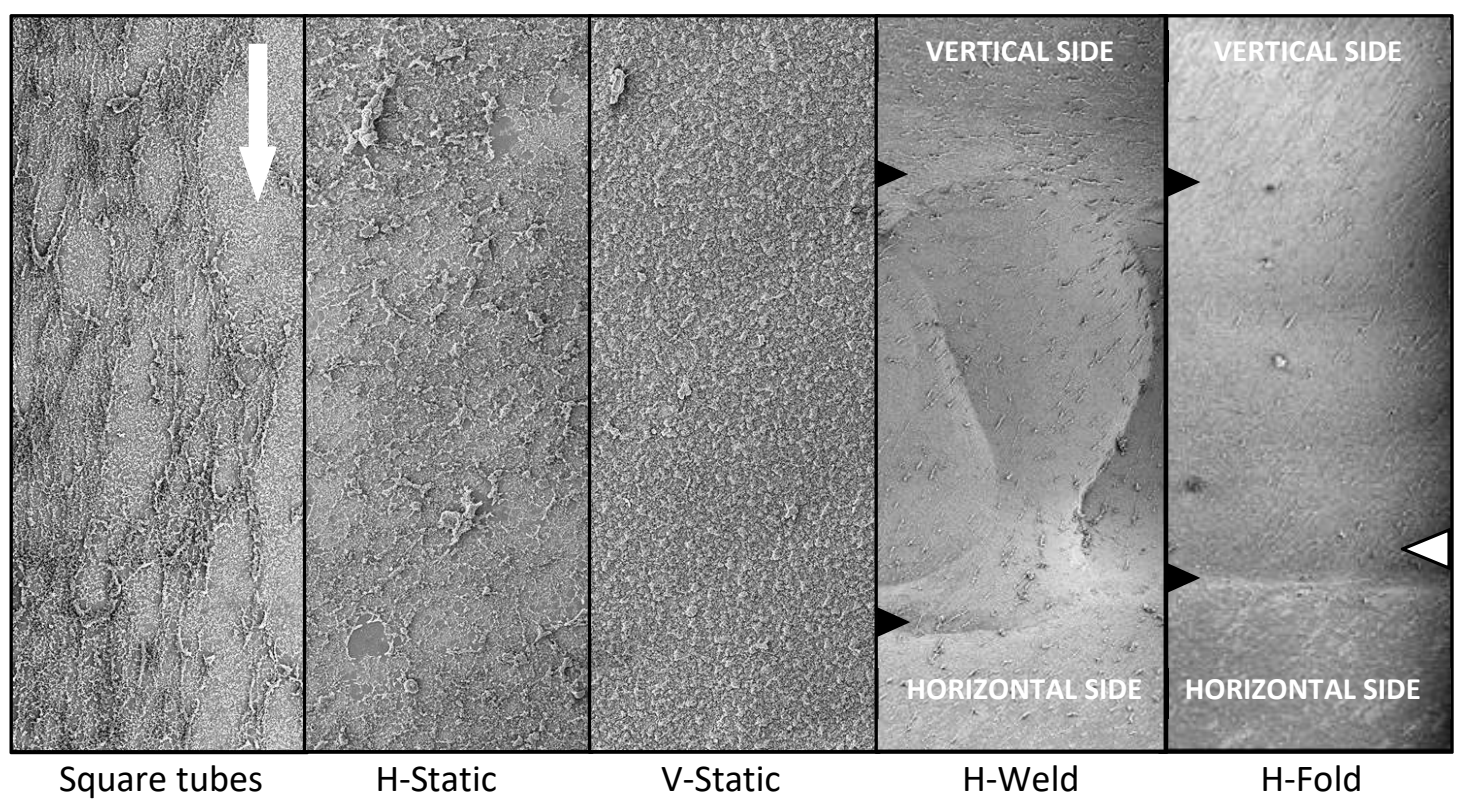

Figure 1: SEM observation of $72 \mathrm{~h}$-biofilms. The white arrows indicate the flow direction. The black triangles indicate the top and bottom threshold between which the angle is located. The white triangle indicates the score line of the folded slides. Magnification x70. 


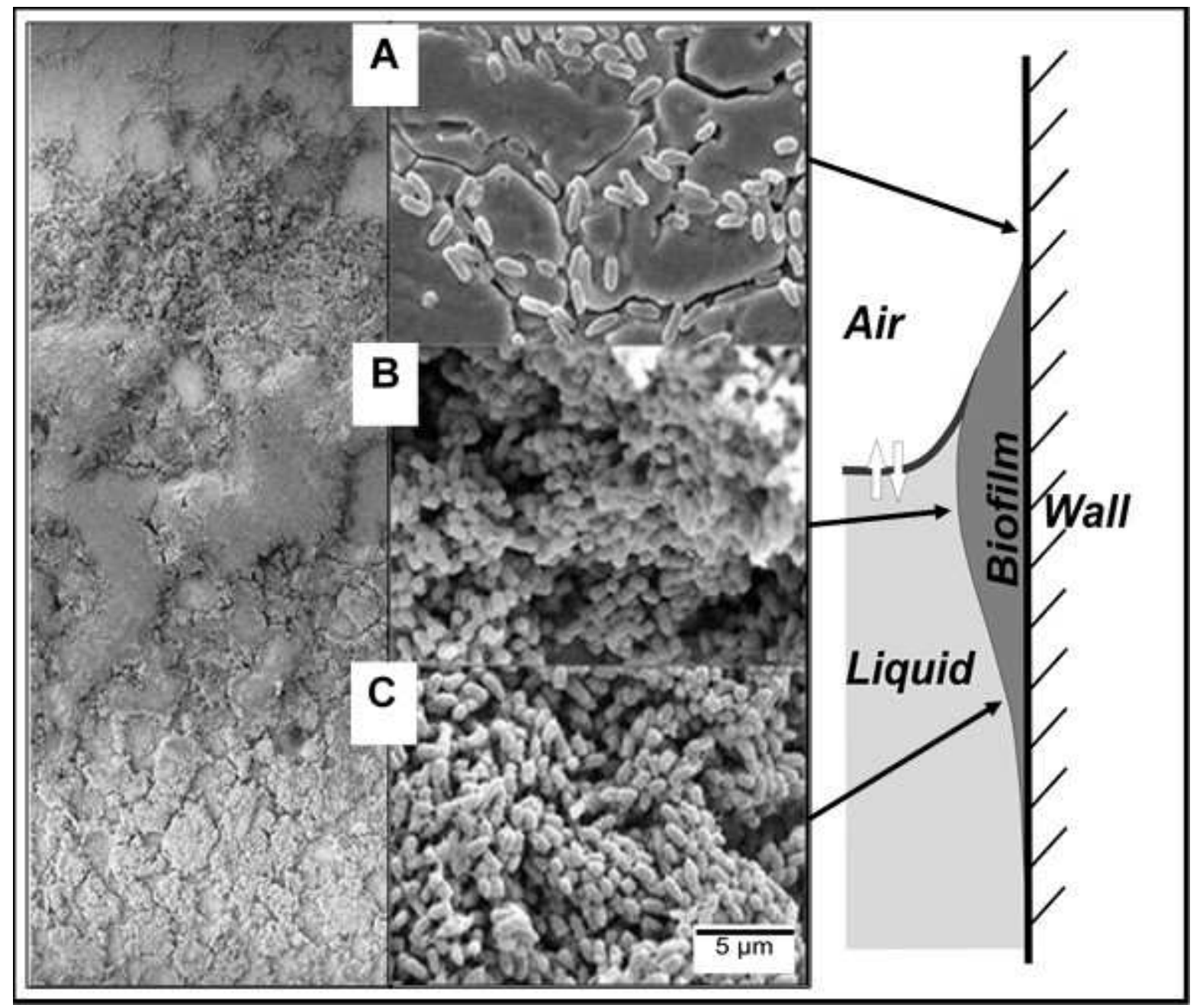

Figure 3: SEM observation of the wetting front (interface). Left part: magnification $x 70$. Right part: magnification $\times 5000$. A, emerged area; $B$, intermittently immersed area; C, immersed area. The white arrows indicate the flow direction. 


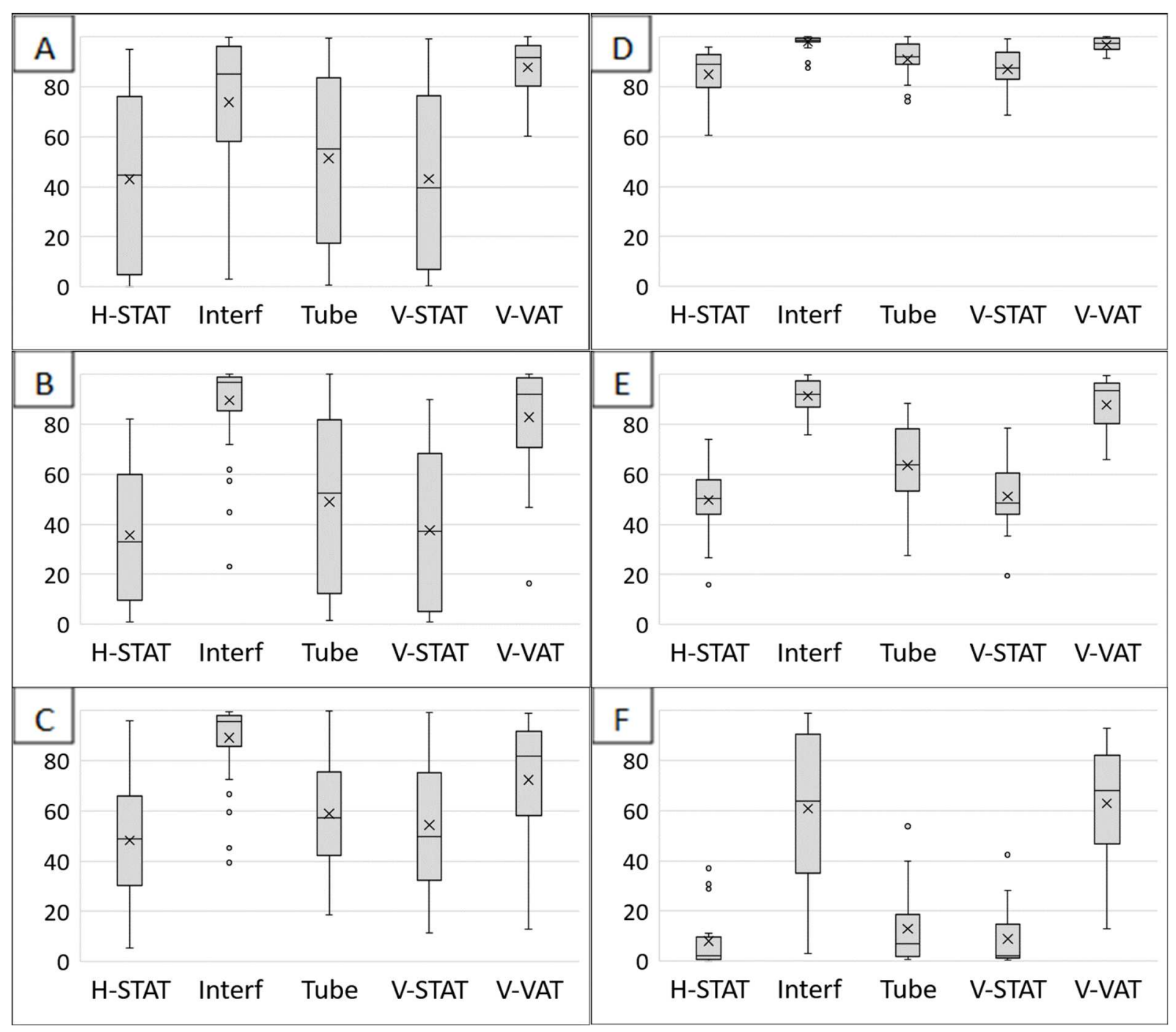

Figure 4: Residual ratio $(x 100)$ of biofilms after mechanical detachment versus areas. $A, B, C$ : shear stress values were not taken into account (A: 24 h-biofilm; B: 48 h-biofilm; C: 72 h-biofilm); D, E, F: times of biofilm formation were not taken into account (C: 17 Pa, D: 130 Pa, E: 360 Pa). 


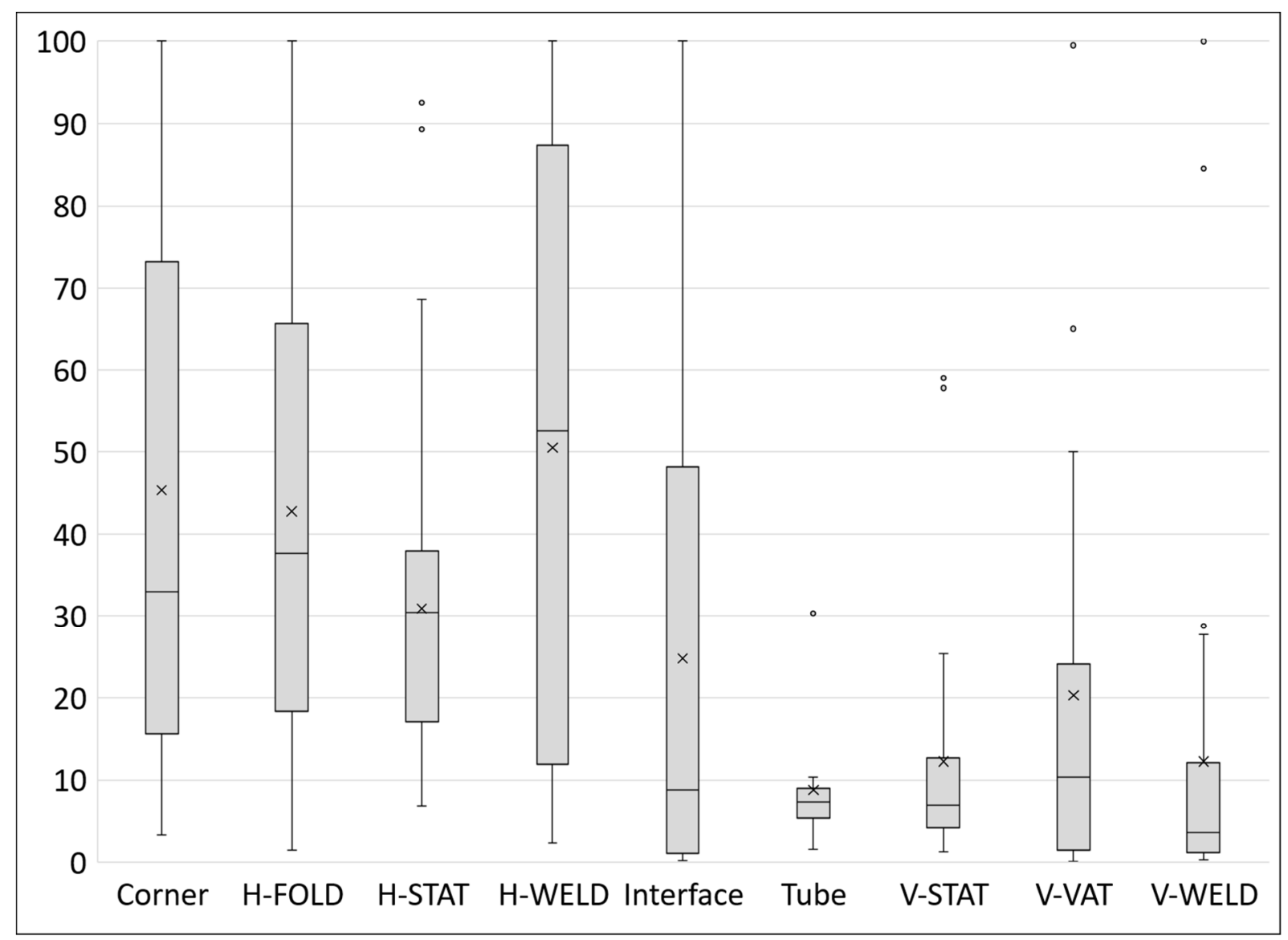

Figure 5: Box plots of the residual ratio $(x 100)$ of biofilms after cleaning by enzymes versus areas, all the data were taken into account whatever the biofilm age. 


\begin{tabular}{|c|c|c|c|c|c|c|c|}
\hline \multirow[b]{3}{*}{ Device } & \multirow[b]{3}{*}{$\begin{array}{l}\text { Location/ } \\
\text { Geometry }\end{array}$} & \multirow[b]{3}{*}{$\begin{array}{l}\text { Flow condition and } \\
\text { average wall shear } \\
\text { stress [WSS] }\left(\bar{\tau}_{w}\right)\end{array}$} & \multirow[b]{3}{*}{$\begin{array}{l}\text { Sample } \\
\text { name }\end{array}$} & \multicolumn{4}{|c|}{ Biofilm } \\
\hline & & & & \multicolumn{2}{|c|}{ Formation } & \multicolumn{2}{|c|}{ Removal } \\
\hline & & & & 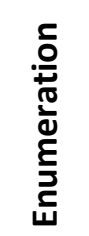 & $\sum_{\tilde{n}}$ & 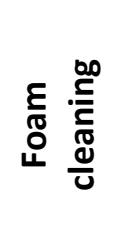 & 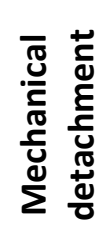 \\
\hline Tubes & Bottom/Flat & $1-\mathrm{D}$ flow $\bar{\tau}_{\mathrm{w}}=0.45 \mathrm{~Pa}$ & $\begin{array}{l}\text { Square } \\
\text { tubes }\end{array}$ & $x$ & $x$ & $x$ & $x$ \\
\hline \multirow[t]{2}{*}{ Entry vat } & Bottom/Flat & Static $\bar{\tau}_{w}<0.01 \mathrm{~Pa}$ & H-Static & $x$ & $x$ & $x$ & $x$ \\
\hline & Side/Flat & Static $\bar{\tau}_{w}<0.01 \mathrm{~Pa}$ & V-Static & $x$ & $x$ & $x$ & $x$ \\
\hline \multirow{7}{*}{ Test vats } & Bottom/Flat & 3D flow $/ 0.5<\bar{\tau}_{w}<4 \mathrm{~Pa}$ & H-Vat & $x$ & $x^{*}$ & $x$ & \\
\hline & Side/Flat & 3D flow $/ 0.5<\bar{\tau}_{w}<4 \mathrm{~Pa}$ & V-Vat & $x$ & $x$ & $\mathrm{x}$ & $x$ \\
\hline & Side/Flat & Air/Liquid/Wall Interface & Interface & $x$ & $x$ & $\mathrm{x}$ & $x$ \\
\hline & Bottom/Weld & 3D flow $/ 0.1<\bar{\tau}_{w}<5 \mathrm{~Pa}$ & H-Weld & $x$ & $x$ & $x$ & \\
\hline & Side/Weld & 3D flow $/ 0.1<\bar{\tau}_{w}<5 \mathrm{~Pa}$ & V-Weld & $x$ & \multirow{3}{*}{$x$} & $x$ & \\
\hline & Bottom/Fold & 3D flow $/ 0.1<\bar{\tau}_{w}<5 \mathrm{~Pa}$ & H-Fold & $x$ & & $x$ & \\
\hline & $\begin{array}{l}\text { Bottom-Side/ } \\
\text { Fold \& Weld }\end{array}$ & $3 \mathrm{D}$ flow $/ \bar{\tau}_{w}=0.1 \mathrm{~Pa}$ & Corner & $x$ & & $x$ & \\
\hline
\end{tabular}

* Biofilms analysed on the bottom side of the right-angled coupons

Table 1: Description of the locations where coupons were installed and list of the analyses implemented 


\begin{tabular}{|c|c|c|c|c|c|c|c|c|c|c|c|c|c|}
\hline \multirow{3}{*}{$\begin{array}{l}\text { Areas } \\
\text { H-static }\end{array}$} & \multicolumn{3}{|c|}{ Biofilm $24 \mathrm{~h}$} & \multicolumn{5}{|c|}{ Biofilm $48 \mathrm{~h}$} & \multicolumn{5}{|c|}{ Biofilm 72 h } \\
\hline & \multicolumn{2}{|l|}{ Mean } & $\begin{array}{l}\text { Tukey's } \\
\text { grouping }\end{array}$ & \multirow{2}{*}{$\begin{array}{l}\text { Mean } \\
7.892\end{array}$} & \multicolumn{4}{|c|}{$\begin{array}{l}\text { Tukey's } \\
\text { grouping }\end{array}$} & \multirow{2}{*}{$\begin{array}{c}\text { Mean } \\
8.279\end{array}$} & \multicolumn{4}{|c|}{$\begin{array}{l}\text { Tukey's } \\
\text { grouping }\end{array}$} \\
\hline & 6.116 & $A$ & & & $A$ & & & & & A & & & \\
\hline Square Tubes & 5.300 & & B & 7.326 & $A B$ & $3 \mathrm{C}$ & & & 8.161 & A & & & \\
\hline V-Static & 5.925 & A & B & 7.551 & $A B$ & 3 & & & 8.036 & A & B & & \\
\hline Corner & 5.656 & A & B & 6.912 & B & $3 \mathrm{C}$ & & & 7.397 & & B & C & \\
\hline Interface & 3.567 & & $C \quad D$ & 6.026 & & D & $\mathrm{E}$ & & 7.359 & & & C & \\
\hline H-Vat & 3.080 & & D & 5.539 & & & E & $\mathrm{F}$ & 7.134 & & & C & \\
\hline V-Weld & 3.872 & & C & 5.051 & & & & $\mathrm{~F}$ & 7.031 & & & C & \\
\hline H-Weld & 5.226 & & B & 6.576 & & $C D$ & & & 6.833 & & & & D \\
\hline H-Fold & 3.392 & & $C D$ & 5.750 & & & $E$ & $\mathrm{~F}$ & 6.349 & & & & D \\
\hline V-Vat & 0.849 & & $\mathrm{E}$ & 3.507 & & & & G & 5.492 & & & & $\mathrm{E}$ \\
\hline
\end{tabular}

${ }^{a}$ Following Tukey's grouping, areas with no common letter are significantly different.

Table 2: Amounts of biofilms produced in the different locations and grouping of biofilms, according to the Tukey's grouping ( $p$-value $<0.05$ ) 


\begin{tabular}{lccccc}
\cline { 2 - 6 } & \multicolumn{2}{c}{ Model } & \multicolumn{3}{c}{ Parameters } \\
taken into account
\end{tabular}

Table 3. Information obtained from the analysis of variance achieve to investigate the role of Coupon location, trial and biofilm age on the amount of biofilm. A further grouping of biofilms was performed according to the Tukey's grouping ( $p$-value $<0.05$ ) 


\begin{tabular}{|c|c|c|c|c|c|c|}
\hline \multirow[b]{2}{*}{ Model } & \multicolumn{2}{|c|}{ Model } & \multicolumn{4}{|c|}{ Parameters taken into account } \\
\hline & $\operatorname{Pr}>\mathrm{F}$ & $\mathbf{R}^{2}$ & $\begin{array}{c}\operatorname{Pr}>\mathrm{F} \\
\text { Location }\end{array}$ & $\begin{array}{c}\operatorname{Pr}>\mathrm{F} \\
\text { Trial }\end{array}$ & $\begin{array}{l}\text { Pr }>F \\
\text { Time }\end{array}$ & $\begin{array}{l}\mathrm{Pr}>\mathrm{F} \\
\text { WSS }\end{array}$ \\
\hline \multicolumn{7}{|c|}{ Mechanical detachment (biofilm 24, 48 \& 72 h) } \\
\hline All WSS & $<.0001$ & 0.7535 & $<.0001$ & 0.0005 & 0.1162 & $<.0001$ \\
\hline WSS $17 \mathrm{~Pa}$ & $<.0001$ & 0.5450 & $<.0001$ & 0.0040 & 0.0580 & - \\
\hline WSS $60 \mathrm{~Pa}$ & $<.0001$ & 0.7077 & $<.0001$ & 0.0029 & 0.1481 & - \\
\hline WSS $130 \mathrm{~Pa}$ & $<.0001$ & 0.7433 & $<.0001$ & 0.0388 & 0.5130 & - \\
\hline WSS $190 \mathrm{~Pa}$ & $<.0001$ & 0.7682 & $<.0001$ & 0.0752 & 0.5777 & - \\
\hline WSS $275 \mathrm{~Pa}$ & $<.0001$ & 0.7414 & $<.0001$ & 0.8857 & 0.0302 & - \\
\hline WSS $360 \mathrm{~Pa}$ & $<.0001$ & 0.6637 & $<.0001$ & 0.9987 & 0.0202 & - \\
\hline \multicolumn{7}{|c|}{ Enzymatic cleaning (biofilm 24, 48 \& 72 h) } \\
\hline WSS $0 \mathrm{~Pa}$ & $<.0001$ & 0.2569 & $<.0001$ & 0.0122 & 0.9100 & - \\
\hline
\end{tabular}

Table 4. Influence of the sample, trial, time of biofilm formation and shear stress on the ratio of residual biofilm. Two analyses of variance were performed for the mechanical detachment. The first analysis took into account the whole set of data $(17,60,130,190,275$, and $360 \mathrm{~Pa})$. In the second analysis, each wall shear stress was analysed separately. The third analysis concerns enzymatic cleaning data. 


\begin{tabular}{cccccc} 
& \multicolumn{5}{c}{ Tukey's grouping $^{\mathrm{a}}$} \\
\cline { 2 - 6 } Table 5.1 & Interface & V-VAT & Tube & V-STAT & H-STAT \\
\hline WSS & A & A & B & BC & C \\
$17 \mathrm{~Pa}$ & A & A & B & C & C \\
$60 \mathrm{~Pa}$ & A & B & B & C & C \\
$130 \mathrm{~Pa}$ & A & A & B & BC & C \\
$190 \mathrm{~Pa}$ & A & A & B & B & B \\
$275 \mathrm{~Pa}$ & A & A & B & B & B \\
$360 \mathrm{~Pa}$ & & & & & \\
\hline
\end{tabular}

\begin{tabular}{ccccccccc}
\cline { 2 - 7 } \multicolumn{2}{c}{ Table 5.2 } & \multicolumn{7}{c}{ Tukey's grouping $^{\mathrm{a}}$} \\
\hline H-WELD & Corner & H-FOLD & H-STAT & Interface & V-VAT & V-WELD & V-STAT & Tube \\
\hline $\mathrm{A}$ & $\mathrm{AB}$ & $\mathrm{AB}$ & $\mathrm{AB}$ & $\mathrm{ABC}$ & $\mathrm{BC}$ & $\mathrm{C}$ & $\mathrm{C}$ & $\mathrm{C}$ \\
\hline
\end{tabular}

${ }^{a}$ Following Tukey's grouping, areas with no common letter are significantly different in terms of ease of removal; group $A$ is the most resistant to detachment whereas group $C$ is the least resistant.

Table 5: Tukey's grouping of biofilms according to their resistance to mechanical detachment (Table 5.1) and enzyme cleaning including bend surfaces (Table 5.2) ( $p$-value $<0.05$ ) 